\title{
KANDUNGAN C-ORGANIK TANAH DAN TOTAL NITROGEN PADA TANAH VERTISOL YANG TELAH DIBAKAR DAN TIDAK DIBAKAR
}

\author{
Ana Juliana Ome', W. I . I Mella², Manuel Pian³ \\ Deviome@ymail.com \\ Minat Manajemen Sumber Daya Lahan, Jurusan Agroteknologi \\ Fakultas Pertanian Universitas Nusa Cendana
}

\begin{abstract}
The use of fire in agriculture land preparation may result in the change of various soil properties. Therefore, a study was conducted in the village of Oeteta, Kupang to determine soil total organic-C and total nitrogen of burned and un burned Vertisols. Randomized complete block design with two factors was applied. The first factor was burning treatment with two levels: burned and un burned. The second factor was soil depth with three levels: 0$10 \mathrm{~cm}, 11-20 \mathrm{~cm}$ and $21-30 \mathrm{~cm}$; all together made up 54 experimental units. Results showed that in all depths there was no significant difference in total soil organic-C between burned and un burned soils. However total soil organic-C contents in both burning treatments was considered high. Similary, the was also no significant difference in total soil nitrogen between burned and un burned plots. Total soil $\mathrm{N}$ was considered in high and medium levels for burned and un burned soil respectively. In summary, burning does not affect soil total organic-C contents but reduces soil total $\mathrm{N}$ contents.
\end{abstract}

Keywords: total soil organic carbon, total soil nitrogen, soil depth, Vertisols soil burning.

\section{PENDAHULUAN}

Penyiapan lahan dengan

menggunakan api sudah sejak lama

dikenal oleh masyarakat Nusa Tenggara

Timur (Woha, 2001). Dilihat dari

prespektif petani penyiapan lahan dengan

menggunakan api memiliki manfaat,

antara lain dalam meyediakan ruang untuk

bercocok tanam, memberikan abu sebagai

pupuk, mengurangi kompetisi tanaman, dan mengurangi timbulnya hama dan penyakit.

Pembakaran juga berdampak pada ketersediaan hara dalam tanah, khususnya unsur hara yang bersifat mobile atau mudah menguap. Hasil penelitian Hidayat (2004), sesaat setelah pembakaran padang rumput di Kabupaten Sumba Timur dan Kabupaten Ende menunjukan konsentrasi unsur hara nitrogen menurun. Hasil penelitian dari Ketterings and Bigham 
Ana: Kandungan c-organik tanah dan total nitrogen pada tanah vertisol yang telah dibakar dan tidak dibakar

(2000) menunjukan tanah mengalami

kehilangan nitrogen total dan kandungan

C-organik tanah 2 minggu setelah

kebakaran. menurut hasil penelitian

Yusudarso (2001) yaitu terjadi penurunan

kandungan C-organik tanah sesaat setelah

pembakaran lahan sedangkan kandungan

nitrogen total tanah menurun sesaat setelah

pembakaran dan delapan bulan setelah

pembakaran juga terjadi penurunan.

Kandungan nitrogen tanah juga

berhubungan dengan mikroorganisme

tanah yang dapat mengikat nitrogen, akibat

pembakaran mikroorganisme mati. Dengan

matinya organisme yang dapat mengikat

nitrogen tersebut maka, kandungan

nitrogen dalam tanah menurun. Selain

berperan dalam fiksasi dan transformasi

nitrogen, organisme tanah juga berperan

dalam dekomposisi bahan organik dan

translokasi hara. Menurut Hanafiah (2012),

bahan organik juga mempengaruhi

kandungan karbon karena komponen yang

paling besar dalam bahan organik adalah karbon. Karbon merupakan sumber makanan organisme tanah, dengan penurunan bahan organik tanah, menurunkan aktivitas mikroorganisme tanah. Hasil penelitian Djunaidi (1999) pembakaran lahan menurunkan populasi fungi, total mikroorganisme tanah dan Azotobacter bakteri penambat nitrogen.

Unsur Nitrogen berkorelasi sangat erat dengan perkembangan jaringan meristem sehingga sangat menentukan pertumbuhan tanaman (Hanafiah, 2012). Nitrogen kahat pada tanah Vertisol, unsur hara tersebut terjepit dalam interlayer, yaitu merupakan ruang antara dua lembaran tetrahedral dengan octahedral (2:1) yang mempunyai diameter sama dengan diameter $\mathrm{N}$, sehingga $\mathrm{N}$ akan terjepit didalamnya, akibatnya tanah ini menjadi kekurangan N. (Brady and Weil, 2004).

Hasil penelitian Wasis (2003) di Kalimantan tengah, Riau, dan Garut tentang pembersihan lahan dengan cara 
Ana: Kandungan c-organik tanah dan total nitrogen pada tanah vertisol yang telah dibakar dan tidak dibakar

pembakaran lahan secara disengaja, pada

tanah gambut dan mineral menyebabkan terjadi peningkatan kandungan hara seperti $\mathrm{N}, \mathrm{P}, \mathrm{K}, \mathrm{Ca}, \mathrm{Mg}$ dan $\mathrm{Na}$ serta bahan organik tanah. selanjutnya menurut Lal (1987) terjadi peningkatan yang signifikan total nitrogen dan C-Organik tanah setelah satu minggu pembakaran. Jadi kandungan C-Organik dan Nitrogen pada lahan pertanian tanah Vertisol yang dibakar dan yang tidak dibakar mungkin akan sama atau akan berbeda.

\section{METODOLOGI PENELITIAN}

Penelitian ini telah dilaksanakan di Desa Oeteta sedangkan analisis dilakukan di Laboratorium Kimia Tanah Fakultas Pertanian Nusa Cendana. Penelitian berlangsung dari bulan November 2012 sampai Februari 2013.

Bahan - bahan yang digunakan dalam penelitian ini adalah tanah Vertisol, bahan analisis laboratorium dan kertas label dan plastik sampel. Alat yang digunakan dalam penelitian ini adalah
GPS, Tali, Karung kamera, mistar, linggis, timbangan, alat-alat analisis laboratorium, dan alat tulis-menulis.

Penelitian ini merupakan percobaan faktorial yang menggunakan rancangan dasar RAK (rancangan acak kelompok dengan 2 perlakuan yang terdiri dari 2 taraf yaitu keadaan tanah (tanah yang telah dibakar dan tanah yang tidak dibakar) dan kedalaman tanah $(0-10 \mathrm{~cm}, 11-20 \mathrm{~cm}, 21-$ $30 \mathrm{~cm})$ dan 9 ulangan. Data yang dikumpulkan akan dianalisis dengan menggunakan sidik ragam (Anova) untuk mengetahui apakah ada beda nyata pada keadaan tanah dan kedalaman tanah ataupun interaksi antara keduanya, Sedangkan untuk mengetahui variasi kandungan Nitrogen dan C-organik menggunakan selangkepercayaan dengan derajat kesalahan 0,5 .

\section{HASIL DAN PEMBAHASAN Pengamatan Umum}

Penelitian ini dilakukan pada lahan pertanian lahan kering milik petani Desa Oeteta yang berlangsung pada tanggal 29 
Ana: Kandungan c-organik tanah dan total nitrogen pada tanah vertisol yang telah dibakar dan tidak dibakar

November, tanah yang dijadikan sampel penelitian yaitu sampel tanah yang telah dibakar dan tidak dibakar, diambil secara acak pada kedalaman $0-10 \mathrm{~cm}, 11-20 \mathrm{~cm}$, dan $21-30 \mathrm{~cm}$. Tanah diambil dari sembilan titik yang berbeda pada satu lokasi yang sama, pada dua jenis keadaan tanah yakni tanah yang telah dibakar dan tanah yang tidak dibakar.

Tanah yang diambil dari sembilan titik dalam satu lokasi yang sama ini adalah lahan pertanian yang menerapkan penggunaan api sebagai satu-satunya metode pembersihan lahan sejak awal pembukaan lahan. Pemilihan lahan ini bertujuan agar dapat mengetahui kandungan karbon organik dan total nitrogen pada tanah Vertisol yang telah dibakar dan yang tidak dibakar serta status haranya pada masa sebelum petani melakukan penanaman atau pada waktu persiapan tanam. Vegetasi yang paling dominan pada lokasi pengambilan sampel tanah yaitu berbagai jenis rumput- rumputan, semak seperti kirinyu (Chromolaena odorata) dan beberapa jenis pohon tahunan seperti jambu mente (Anacardium occidentale), gamal dan lamtoro (Leucaena leucocephala).

Tanah yang diambil dalam keadaan basah sehingga dibutuhkan waktu 8 hari untuk dikering-anginkan sebelum dianalisis kandungan C-organik dan nitrogen di laboratorium kimia tanah. Analisis tanah dilakukan pada tanggal 16 Desember 2012 yaitu pada saat kondisi sampel tanah telah kering dan dapat diayak.

\section{C-organik Tanah}

Hasil analisis keragaman menunjukan bahwa terdapat pengaruh tidak nyata pada interaksi dari keadaan tanah dan kedalaman tanah. Hal ini menunjukan bahwa keadaan tanah dan kedalaman tanah tidak mampu menciptakan keragaman kandungan COrganik tanah. Data rerata kandungan Corganik tanah akibat perlakuan macam 
Ana: Kandungan c-organik tanah dan total nitrogen pada tanah vertisol yang telah dibakar dan tidak dibakar

kedalaman tanah dan keadaan tanah dapat dilihat pada tabel 2.1.

Pada Tabel 2.2 secara umum dapat dilihat bahwa kandungan C-Organik pada tanah yang telah terbakar maupun tanah tidak terbakar memiliki kandungan COrganik yang berkisar dari kategori sedang hingga tinggi, hal tersebut disebabkan karena tanah yang digunakan sebagai sampel penelitian berasal dari biomasa tebangan dan lapisan organik tanah yang dibakar yang dapat menyumbangkan karbon pada tanah sehingga kandungan COrganiknya berada pada kategori tinggi.

Hasil analisis keragaman menunjukan tidak ada pengaruh yang nyata pada kedalaman tanah. Secara umum dapat dilihat bahwa ada kecenderungan penurunan kandungan C-Organik pada setiap kedalaman. Hal ini sesuai dengan pendapat Pairunan (1985) bahwa kandungan bahan organik tertinggi adalah tanah berada pada permukaan, karena adanya proses pelapukan sisa-sisa mikroorganisme yang mati dan berakumulasi pada permukaan tanah. Hal tersebut sesuai dengan pernyataan Hardjowigeno (1992), bahwa tanah yang mengandung bahan organik adalah tanah titik atas atau top soil, karena semakin ke bawah suatu titik tanah maka kandungan bahan organiknya semakin berkurang sehingga tanah menjadi keras. Pada penelitian ini ditemukan bahwa \% COrganik pada lahan yang tidak terbakar lebih tinggi dibandingkan lahan yang telah dibakar, hal ini diduga pembakaran pembakaran yang dilakukan petani pada intensitas yang tinggi sehingga terjadi kehilangan karbon.

\section{Nitrogen Total Tanah}

Hasil analisis keragaman terhadap nitrogen total tanah menunjukan bahwa terdapat pengaruh yang tidak nyata antara interaksi jenis keadaan tanah dan kedalaman tanah. Berdasarkan data pada tabel 3.1 dapat dilihat bahwa pada tanah yang telah dibakar dan tanah yang tidak 
Ana: Kandungan c-organik tanah dan total nitrogen pada tanah vertisol yang telah dibakar dan tidak dibakar

bakar pada kedalaman $0-10 \mathrm{~cm}, 11-20 \mathrm{~cm}$ dan $30 \mathrm{~cm}$ tidak berpengaruh nyata terhadap kandungan $\%$ total nitrogen tanah.

Pada tabel 3.1 dapat dilihat bahwa data hasil penelitian rerata kandungan total nitrogen di tanah yang telah dibakar lebih tinggi dibandingkan dengan tanah yang tidak dibakar. Secara umum data kandungan nitrogen total tanah pada tanah yang telah dibakar termaksud dalam kelompok kategori sedang (Hardjowigeno dan Widiatmaka, 2007), sedangkan pada tanah yang tidak terbakar termaksud dalam kategori tinggi. Hasil penelitian Yosudarso (2001) menunjukan bahwa kandungan Ntotal sesaat setelah dibakar menurun sebesar $0,05 \%$ dan pada periode 8 bulan setelah dibakar juga menunjukan penurunan sebesar $0,02 \%$ Rerata kandungan total nitrogen tanah pada tanah yang dibakar kedalaman 0-10cm, 11$20 \mathrm{~cm}, 21-30 \mathrm{~cm}$ lebih rendah daripada tanah yang tidak dibaka. Pembersihan lahan dengan metode pembakaran dapat menaikan suhu tanah yang dapat menyebabkan nitrogen berupa ammonium dan nitrat menguap.

Kandungan nitrogen juga berhubungan dengan mikroorganisme tanah yang dapat mengikat nitrogen, akibat pembakaran mikroorganisme tersebut mati, dengan matinya mikroorganisme yang dapat mengikat nitrogen tersebut kandungan total nitrogen tanah menurun. Jumlahnya sangat tergantung pada tempat dan iklim (Hakim, 1986). Selanjutnya menurut Hardjowigeno, (2003) hilangnya $\mathrm{N}$ dari tanah selain karena digunakan oleh tanaman atau mikroorganisme, $\mathrm{N}$ dalam bentuk $\mathrm{NH}_{4}{ }^{+}$dapat diikat oleh mineral liat jenis illit sehingga tidak dapat digunakan oleh tanaman.

Perbandingan Karbon- Nitrogen pada Tanah yang dibakar dan Tanah yang Tidak di Bakar

Nitrogen adalah zat yang dibutuhkan bakteri penghancur untuk bertumbuh dan berkembang biak, rasio $\mathrm{C} / \mathrm{N}$ adalah 
Ana: Kandungan c-organik tanah dan total nitrogen pada tanah vertisol yang telah dibakar dan tidak dibakar

perbandingan karbon dan nitrogen dalam satu bahan. Rasio Carbon-Nitrogen (C/N) merupakan cara untuk menunjukkan gambaran kandungan Nitrogen relatif. Rasio $\mathrm{C} / \mathrm{N}$ dari bahan organik juga merupakan petunjuk kemungkinan kekurangan nitrogen dan persaingan di antara mikroba-mikroba dan tanaman tingkat tinggi dalam penggunaan nitrogen yang tersedia dalam tanah (Foth, 1991). Menurut Winarso (2005), Bahan organik yang memiliki $\mathrm{C} / \mathrm{N}$ dibawah 20 dalam beberapa minggu sudah akan melepaskan unsur yang dikandungnya, khususnya $\mathrm{N}$ atau terjadi mineralisasi.

Data hasil penelitian menunjukan bahwa pada tanah yang telah dibakar memiliki $\mathrm{C} / \mathrm{N}$ rasio lebih tinggi dibandingkan tanah yang tidak dibakar, hal ini dikarenakan pada tanah yang tidak dibakar memiliki kandungan nitrogen yang lebih tinggi daripada tanah yang dibakar (tabel 4.1), ini telah buktikan dalam penelitian sebelumnya dari Djunaidi
(1999), Hasil penelitian nya menunjukan pembakaran lahan menurunkan populasi fungi, total mikroorganisme tanah dan Azotobacter bakteri penambat nitrogen, selain itu jenis tanaman dan jumlah sisa tanaman yang ditambahkan ke tanah juga turut mempengaruhi perbandingan karbon dan nitrogen. Secara umum kedua lahan ini memiliki perbandingan karbon dan nitrogen yang sangat rendah yaitu dibawah 10, seperti yang di miliki oleh top soil tanah tidak terganggu (Winarso, 2005).

Kandungan Karbon Organik dan Total Nitrogen pada Tanah Dibakar dan Tanah yang Tidak Terbakar

Pengukuran simpanan karbon dan nitrogen pada tanah Vertisol penting dilakukan selain untuk menginventarisasi besarnya simpanan karbon dan nitrogen, juga untuk monitoring besarnya perubahan simpanan karbon dan nitrogen sebagai dampak perubahan sistem pengelolaan lahan (Dariah et all, 2012). Luasan lahan 1 hektar pada kedalaman tanah $30 \mathrm{~cm}$, berat 
Ana: Kandungan c-organik tanah dan total nitrogen pada tanah vertisol yang telah dibakar dan tidak dibakar

tanah yaitu $6000.000 \mathrm{~kg}$ dengan jumlah karbon yang terkandung dalam tanah yang telah dibakar sebanyak 182,400 kg dengan perkiraan jumlah $\mathrm{CO}_{2}$ yang dilepas ke atmosfir sebanyak $676,880 \mathrm{~kg}$ lebih rendah daripada kandungan karbon pada tanah yang tidak dibakar yaitu $232,800 \mathrm{~kg}$ dengan jumlah karbon dioksida 861,360 $\mathrm{kg}$. Jumlah nitrogen yang ada dalam tanah yang telah dibakar sebanyak $28.200 \mathrm{~kg}$ dan pada tanah yang tidak dibakar sebanyak 39.600 kilogram nitrogen.

\section{Kesimpulan}

Kandungan total nitrogen tanah pada kedalaman $0-10 \mathrm{~cm}, 11-20 \mathrm{~cm}$ dan 21-30 cm di tanah yang telah dibakar berbeda tidak nyata dibandingkan dengan tanah yang tidak dibakar tetapi $\% \mathrm{~N}$ total tanah pada tanah yang tidak dibakar termaksud dalam kategori tinggi sedangkan tanah yang telah dibakar termaksud dalam kategori sedang jika dilihat dari nilai dan kriteria \% total nitrogen dalam tanah.

\section{UCAPAN TERIMA KASIH}

Pada kesempatan ini penulis ingin mengucapkan terima kasih kepada semua pihak yang telah membantu dengan caranya masing-masing dalam melengkapi tulisan ini.

\section{DAFTAR PUSTAKA}

Agus, F. dan I G.M. Subiksa. 2008. Lahan Gambut: Potensi Untuk Pertanian Dan Aspek Lingkungan. Balai Penelitian Tanah. Badan Litbang Pertanian. World Agroforestry Centre. Bogor.

Berita Resmi Statistik Provinsi Nusa Tenggara Timur Produksi Tanaman Padi dan Palawija NTT (Angka Tetap 2010 \& Angka Ramalan II 2011) No. 02/07/53/Th.XIV, 1 Juli 2011

Berkes, F., Colding, J. dan Folke, C. 2000. Rediscovery of Traditional Ecological Knowledge as Adaptive Management. Ecological Applications. Vol. 10. No. 5. p 1251-1262.

BMKG Lasiana Kupang. Data Klim Bulanan-Lasiana 2000-2012

Buckman, H. O dan N, C Brady, 1982. Ilmu Tanah. Penerbit Bharata Karya Aksara. Jakarta

Budi, S, S. 2012. Pendugaan Emisi CO2 Berdasarkan Kedalaman Drainase Akibat Alih Guna Lahan. (Studi Kasus: Daerah Eks Proyek Lahan Gambut Sejuta Hektar, Kalimantan Tengah). Skripsi IPB.

Brady, N, C and R, R Weil. 2002. The Nature An Properties Of Soils. Prentice Hall. New Jersey 2004. Elements of the Nature and Properties of Soils. Pearson Education, Inc., Upper Saddle River, New Jersey

Comerma, J. 1999. Soil Taxonomy. A Basic System of Soil Classification for Making and Interpreting Soil Surveys. 
Ana: Kandungan c-organik tanah dan total nitrogen pada tanah vertisol yang telah dibakar dan tidak dibakar

United States Department of Agriculture Natural Resources Conservation Service

Darliana. 2009. Pengaruh Jenis bokasi terhadap bobot isi tanah, C-Organik dan KTK Serta Hasil Daun Teh pada Tanah Andosol asal Gambung.http.4tkipa.phd?id. download 11 November 2012.

Dariah, A, E. Susanti, E. Surmaini, dan F. Agus. 2012. Karbon tersimpan di lahan gambut dengan berbagai penggunaan di Kabupaten Kubu Raya dan Pontianak, Kalimantan Barat. Disampaikan pada Seminar Nasional Sumberdaya Lahan Pertanian. Balai Besar Litbang Sumberdaya Lahan Pertanian. Badan Litbang Pertanian.Chave dan Brown. 2005. (ICRAF. Carbon Footprint of Indonesian Palm Oil Production: a Pilot Study (leaflet).

Debano, F.L., G, N Daniel, and F, F,Peter. 1998. Fire's Effect On Ecosystems. John Wiley \& Sons, Inc. New York.

Djunaidi.1999. Pengaruh Tebas Bakar terhadap Populasi dan Mikroorganisme tanah. Thesis. Program Pasca Sarjana Institut Pertanian. Bogor.

Drinkwater et al. 1998. Legume-based cropping systems have reduced carbon and nitrogen losses. Nature 396: 262265.

Duchaufour, P. 1982. Pedology, Pedogenesis and classification. George Allen and Unwin. Boston.

Foth H. D. 1998. Dasar-Dasar Ilmu Tanah. Gadjah Mada University Press. Yogyakarta.

Giardina C. P., R. L. Sanford, Jr., and I. C. Døckersmith. 2000. Changes in Soil Phosphorus and Nitrogen During Slashand-Burn Clearing of a Dry Tropical Forest

Hakim, N. 1986. Dasar-Dasar Ilmu Tanah.Universitas Lampung, Lampung

Hanafiah, K, A. 2012. Dasar-Dasar Ilmu Tanah. Rajawali Press. Jakarta
Hardjowigeno, S. 2003. Ilmu Tanah. Akademika Presindo. Jakarta

Hardjowigeno, S dan Widiatmaka. 2007. Evaluasi Kesesuaian Lahan dan Perencanaan Tataguna Lahan. Gadjah Mada University Perss, Yogyakarta

Havlin, J.L., S.L. Tisdale, J.D. Beaton, and W.L. Nelson. 2005. Soil Fertility and

Fertilizers. Pearson Education, Inc., Upper Saddle River, NJ

Herlianto, S, C. 2006. Studi Tentang Sebaran Titik Panas (Hotspot) Sebagai Penduga Kebakaran Hutan Dan Lahan Di Propinsi Kalimantan Barat Tahun 2003 Dan Tahun 2004. Skripsi IPB Bogor.

Hidayat, E, J, E. 2004. Dampak Kebakaran Di Padang Rumput Terhadap Sifat Fisik Dan Kimia Tanah. Skipsi. Institut Pertanian Bogor

Ketterings QM and Bigham M. 2000. Soil color as an indicator of slash-and-burn fire severity and soil fertility in Sumatra, Indonesia. Soil Sci. Soc. Am. J. 64: 1826-1833.

Ladd, J.N., M. Amato., Z, Likai, and J.E Schlutz. 1994. Defferential effect of rotation plant residue and nitrogen fertilizer on microbial biomass and organic matter in Australia Alfisol. Soil Biol. Biochem. 26(7):821-831.

Lal, R. 1987. Tropical Ecology And Physical Edaphologi. Jhon Wiley and Sons. Toronto

Lehman, J. 2007a. A Handfull of Carbon. Nature 447, 143-144.

MacLean D, A., S, J, Woodley., M, G, Weber, dan R, W, Wein. 1983. Fire and Nutrient Cycling. p:111-127 in R, W, Wein and D, A, MacLean (eds).The role of fire in Northern Circupolar Ecosystem. Jhon Wiley and Sons. Toronto.

Oktavia, D. 2006. Perubahan Karbon Organik dan Nitrogen Total Tanah Akibat Perlakuan Pupuk Organik Pada Budidaya Sayuran Organik. Skripsi. IPB Bogor. 
Ana: Kandungan c-organik tanah dan total nitrogen pada tanah vertisol yang telah dibakar dan tidak dibakar

Pairunan, Anna, K., Nanere, J, L., Arifin., Solo, S, R. Samosir, Romoaldus Tangkaisari, J. R Lalapia Mace, Bachrul Ibrahim., Hariadji Asnadi., 1985. Dasar-Dasar Ilmu Tanah. Perguruan Tinggi Negeri Indonesia Timur. Makassar

Palm, C.A., M. Van Nordwijk., P. L Woomer, J. C. Alegre,L. Arévalo, C. E. Castilla, D. G. Cordeiro, K. Hairiah, J. K.Same, A. Moukam, W. J. Parton, A. Ricse, V. Rodrigues, and S. M. Sitompul 2005. Carbon Losses and Sequestration After Land Use Change in the Humid Tropics. Vol. 58. p 49-60. In Palm. C. A., S A. Vosti, P. A. Sanchez, and P.J. Ericksen (Eds). Slash and Burn Agriculture The Search for Alternatives. Columbia University Press. New York.

Subekti, R., L, Betha, dan M, Van Noordwijk. Pendugaan Cadangan Karbon Di Atas Permukaan Tanah Pada Berbagai Sistem Penggunaan Lahan Di Kabupaten Nunukan, Kalimantan Timur.

Statistik Desa Oeteta. 2012-12-11

Soil Survey Staff. 2010. Keys to Soil Taxonomy, Eleventh Edition $\mathrm{ftp}: / / \mathrm{ftpfc}$. sc.egov.usda.gov/NSSC/Soil_ Taxonomy/keys/2010_Keys_to_Soil_T axonomy.pdf. Diakses 11 Januari 2013.

Suwardjo H., Rb. Sunyoto, Wahyunto dan A, Dariah. 1994. Penyebaran Lahan Kritis dan Teknologi Penanggulangannya di Kawasan Timur
Indonesia . Dalam Prosiding: Temu konsultasi Sumberdaya Lahan Untuk Pembangunan Kawasan Timur Indonesia. Palu, 17-20 Januari 1994. Bogor. Pusat Penelitian Tanah dan Agroklimat. Badan Penelitian dan Pengembangan Pertanian.

Wasis, B. 2003. Dampak Kebakaran Hutan Dan Lahan Terhadap Kerusakan Tanah. Jurnal Manajemen Hutan Tropika Vol. IX No. 2 : 79-86. 2002. Manajemen Lahan. Program Studi Ilmu Pengetahuan Kehutanan Program Pascasarjana IPB. Bogor.

Wikipedia. Kjeldahl method. http://en.wikipedia.org/wiki/Kjeldahl_ method. Diakses 25 Januari 20012.

Winarso S. 2005. Kesuburan Tanah Dasar Kesehatan dan Kualitas Tanah.Gava Media. Yogyakarta.

Woha UP. 2001. Pembangunan Pertanian Lahan Kering di NTT. Makalah Seminar Pembangunan Pertanian di Wilayah Kering Indonesia.

Yosudarso, D. I. 2001. Dampak Kebakaran Hutan Terhadap Sifat Fisik dan Kimia Tanah. Skipsi. IPB. Bogor

Yulnafatmawita. 2004. Effects Of Land Use Change On Soil Organic Matter Status Of Bulk And Fractionated Soil Aggregates. Stigma XII (4): Oktober Desember 2004 